\title{
Governmental interventionism degree in economy - a case study in OECD countries
}

\author{
Arik Sadeh $^{1^{*}}$, Claudia Florina Radu ${ }^{2}$, Cristina Feniser ${ }^{3}$, and Ken Brown ${ }^{4}$ \\ ${ }^{1}$ Holon Institute of Technology, Faculty of Technology Management Golomb St. 52, Holon, 5810201, \\ Israel \\ ${ }^{2}$ Vasile Goldiş Western University of Arad, Department of Economic Sciences, Informatics and \\ Engineering, 86 Liviu Rebreanu St., Arad, Romania \\ ${ }^{3}$ Technical University of Cluj Napoca, 28 Memorandumului St. Cluj-Napoca 400114, Romania \\ ${ }^{4}$ Letterkeny Institute of Technology, Port Rd, Letterkenny, Co. Donegal, Ireland
}

\begin{abstract}
In this study, we talk about the economic role of the state, and we analyze the degree of its intervention in the economy within the OECD countries, for the period 2000-2016. Thus, we seek to identify the countries characterized by an active intervention as well as a weaker level of state intervention. Then, we show the types of public spending that the state places more emphasis on. We analyze the distribution of state intervention (given by budget revenues) concerning to GDP, fiscal pressure, the period before and after the 2008 crises and certain types of expenditure. We can say that, generally, well-developed countries are characterized by a high level of state interventionism, while less developed ones by lower interventionism. The degree of interventionism level is smaller after the 2008 crises.
\end{abstract}

\section{Introduction}

The role of the state has changed over time, with many debates and controversies in this regard. Thus, until the Great Depression of the 1930s liberalism was the predominant current, with Adam Smith's laisser-faire principle. Then the decades that followed, until the 1980 s, were characterized by direct state intervention in the economy.

Keynesian ideas have forced the state to take measures to stabilize the economy. Keynesian theory was used to justify an increase in the role of the public sector, because it was needed an economy that reduces exposure to fluctuations [1].

However, towards the end of the 1980s, and early 1990s there was a gradual decrease in state intervention in the economy, that period being characterized by limited interventionism.

Following the more neoliberal tendency of the last two decades of the last century, in the last decade, the emphasis is increasingly on the need and willingness of the State to intervene in economic development. The main reason for this approach is the global economic and financial crisis of recent years and the widespread conviction that it can only be managed through the direct intervention of states [2].

\footnotetext{
* Corresponding author: sadeh@hit.ac.il
} 
Therefore, over time there have been opinions both in favor and against state intervention in the economy. Those who sustain the interventionism are based on arguments such a: market imperfections and shortcomings, the existence of common goods, harmful goods, adverse economic phenomena (unemployment, inflation), the existence of income inequality between individuals. All these are enough reasons to justify a significant state involvement in the economy. Those who are against state interventionism bring as arguments: low efficiency of many actions, high costs of interventionist policies and the fact that often state representatives follow their interests and not of the citizens [3].

One of the reasons for state intervention is to protect individuals against economic risks, but as a result of its intervention, there are significant redistributions of income from highincome individuals to those with lower incomes. The goal is to reduce income inequality (especially through taxation). It is important for the state to focus its attention on making redistributive policies efficient.

We propose to analyze the degree of state intervention in the OECD countries, both in terms of budget revenues and budget expenditures. This way we will identify the higher interventionist countries, but also the weaker interventionist countries.

The paper is structured as follows: Section 2 presents the research literature about the role the state should have in the economy. Section 3 describes the methodology and data used. Section 4 presents the findings, and Section 5 presents the discussions. The paper ends with conclusions.

\section{Literature review}

Collier (2009) argued that the primary role of government is to provide public goods such as protection and justice in exchange of taxes levied, as they are not suitable to be provided privately. Security can be purchased, but there are major limitations in its private provision [4].

Today there are opinions on rethinking the role of the state in the economy because of the economic and financial crisis. Reform of public spending is therefore necessary, but for this it is necessary to improve the functioning of the private market. The state needs to be involved in reforming the market, so he has to play a regulatory role and to become more involved in regulating and providing the necessary information to the public. So the new role of the state involves lower public spending and better markets [5].

We consider that the state should remain involved in providing common goods, because otherwise their existence would be seriously jeopardized. Then the social policy of the state should play an important role in the activities of the state. For these reasons it is necessary for the state to continue to engage actively in essential areas like education, health, pensions, electricity, natural resources of the country - to provide free medical care, and free education [3].

According to Bakala, a good state is the one that guarantees simple, solid, understandable rules for everyone, who does not change these rules and its institutions very often and guarantees the impersonal rule of law and a reliable judicial system. At the same time, the state should provide a good education system and ensure equality not in income but in opportunities [2]. On the other hand, Balcerowicz has the opinion that the only rational approach about the state remains the analytical one. It really implies that the state operates through political leaders and public clerks, who do not differ from ordinary people, being usually interested in themselves and having cognitive limitations [2].

In principle, there are many more things that governments could and should do: provide public goods, correct market failures, reduce inequalities in income and opportunities, stabilize excessive economic fluctuations. But the real difference between success and failure in economic development is made by the necessary institutional and legal 
infrastructures that protect property rights, enforce the rule of law and prevent abuse by governments [6].

\section{Methodology and data}

In our study, we used the data from the OECD database. Data was collected for all OECD countries, from the year 2000 to the year 2016, meaning 17 years. There is data about 34 countries and for the Euro Area. This data is used for the descriptive statistical analysis and analysis of selected variables. Some of the countries contain observations with missing data, so twenty-five countries are included in statistical inference part of the study [7]. Mainly because data for them were available for all variables in the model all over the 17 years. Each variable in the survey has 425 values $(17 * 25=425)$.

First, we make a descriptive analysis on the level of state intervention in OECD countries, both in terms of budget revenues and budget expenditures. Then we analyzed the correlation between state intervention (given by budget revenues) and GDP, fiscal pressure and certain types of expenditure that are most important in the OECD countries budgets.

\section{Findings}

\subsection{Descriptive analysis}

We propose to analyze the degree of state intervention in the OECD countries, given by the share in GDP of both total budgetary revenues and total budget expenditures. For the beginning, we will refer to the share of total budget revenues in GDP. For this, Chart 1 is relevant, showing total budget revenues as a percent of GDP in OECD countries over 20002016. This is the dependent variable of our study and the object of the study.

We see from Chart 1 that the share of total budgetary revenue in GDP of OECD countries can be grouped on three intervals. Thus we have a minimum level between 20 $40 \%$, then an average of $40-50 \%$ and the upper level of $50-60 \%$. The minimum level is registered in 16 countries: Mexico, Australia, Czech Republic, Estonia, Ireland, Japan, Korea, Latvia, New Zealand, Poland, Slovakia, Spain, Switzerland, Turkey, UK, and USA. The average level appears in 13 countries: Austria, Belgium, Canada, Germany, Greece, Hungary, Iceland (except in 2016), Israel, Italy, Luxembourg, Netherlands, Portugal, Slovenia. The maximum level appears in: Denmark, Finland, France, Iceland (2016), Norway, Sweden. We notice that Iceland in 2016 has the highest level of total budget revenues of all OECD countries, close to $58 \%$ of GDP. Also, the euro area average is in the middle range, between $40-50 \%$.

Therefore, most OECD countries are situated in the minimum interval and only 5 of them in the maximum range. In the minimum one, we find mainly non-EU countries, but also 8 EU countries, especially those from South-Eastern Europe (newer EU countries). Within the average interval, mostly are EU countries (except Canada and Israel) - but this is especially the case of well-developed EU countries. Then in the maximum range, as we expected, we mainly find the Northern countries, only France is the exception.

Thus, EU well developed countries have a preference for a rather high level of total budget revenues as a percentage of GDP, which is found in the medium range (40-50\%), but also in the upper (50-60\%) - where we mostly find the Northern countries, known for their high level of taxation and, implicitly, of the budget revenues. Among the newer EU countries, only Hungary and Slovenia are in the middle range, the others following the trend from the non-EU countries such as Korea, New Zealand, the USA, and Mexico. Here, 
as we mentioned before, the level of budget revenues is the lowest (mostly between 30 $40 \%)$.

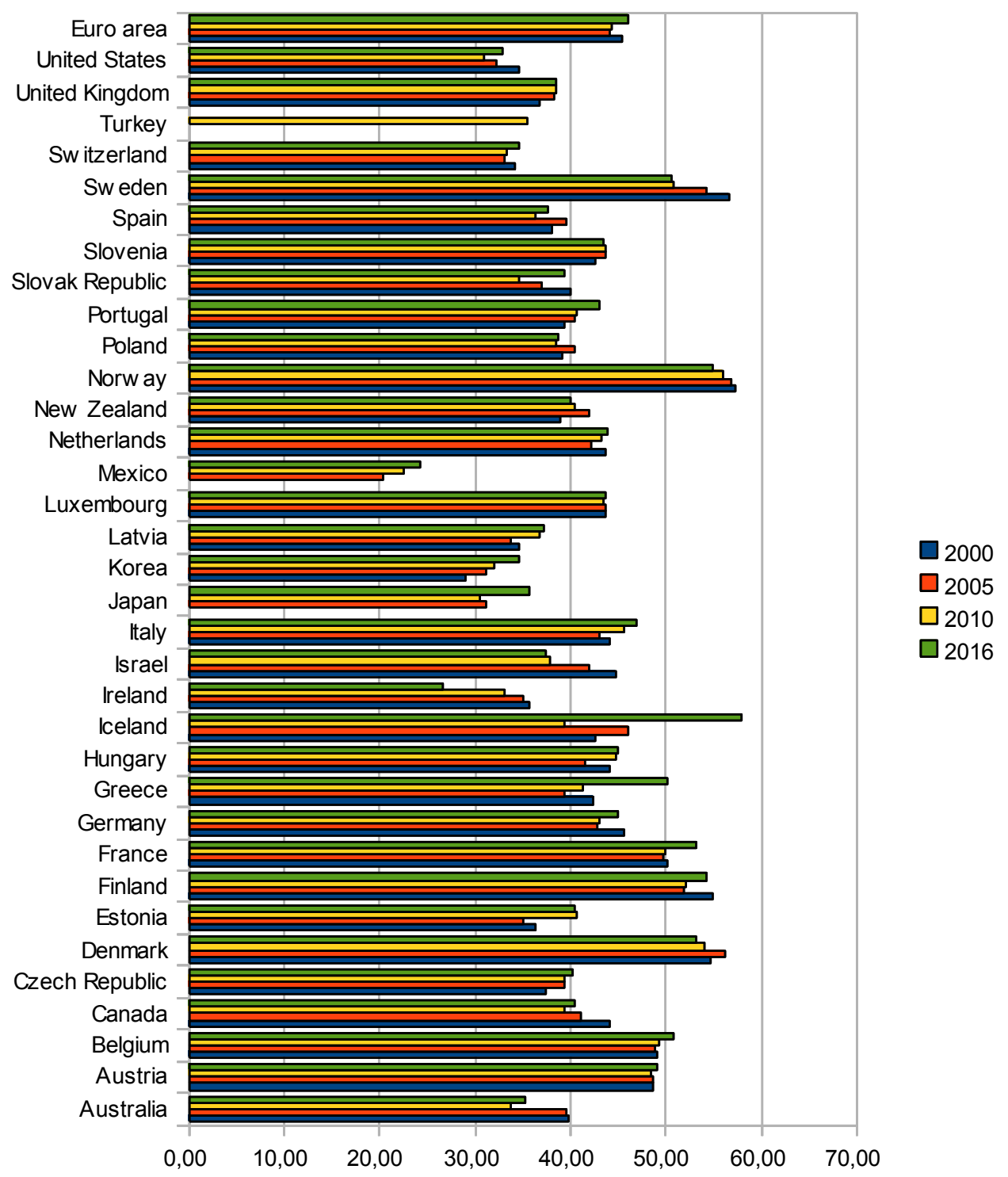

Fig. 1. Total general government revenue (\%GDP) - OECD countries. Source: authors' construction

So, according to Fig. 1, we can say that, generally, well-developed countries are characterized by a high level of state interventionism, while less developed ones by lower interventionism. We also have some exceptions. In countries such as Japan, UK, USA, Australia, the degree of state intervention is more moderate, although they are developed countries. We are talking about their preference for a more liberal doctrine, with less involvement of the state in the economy. 


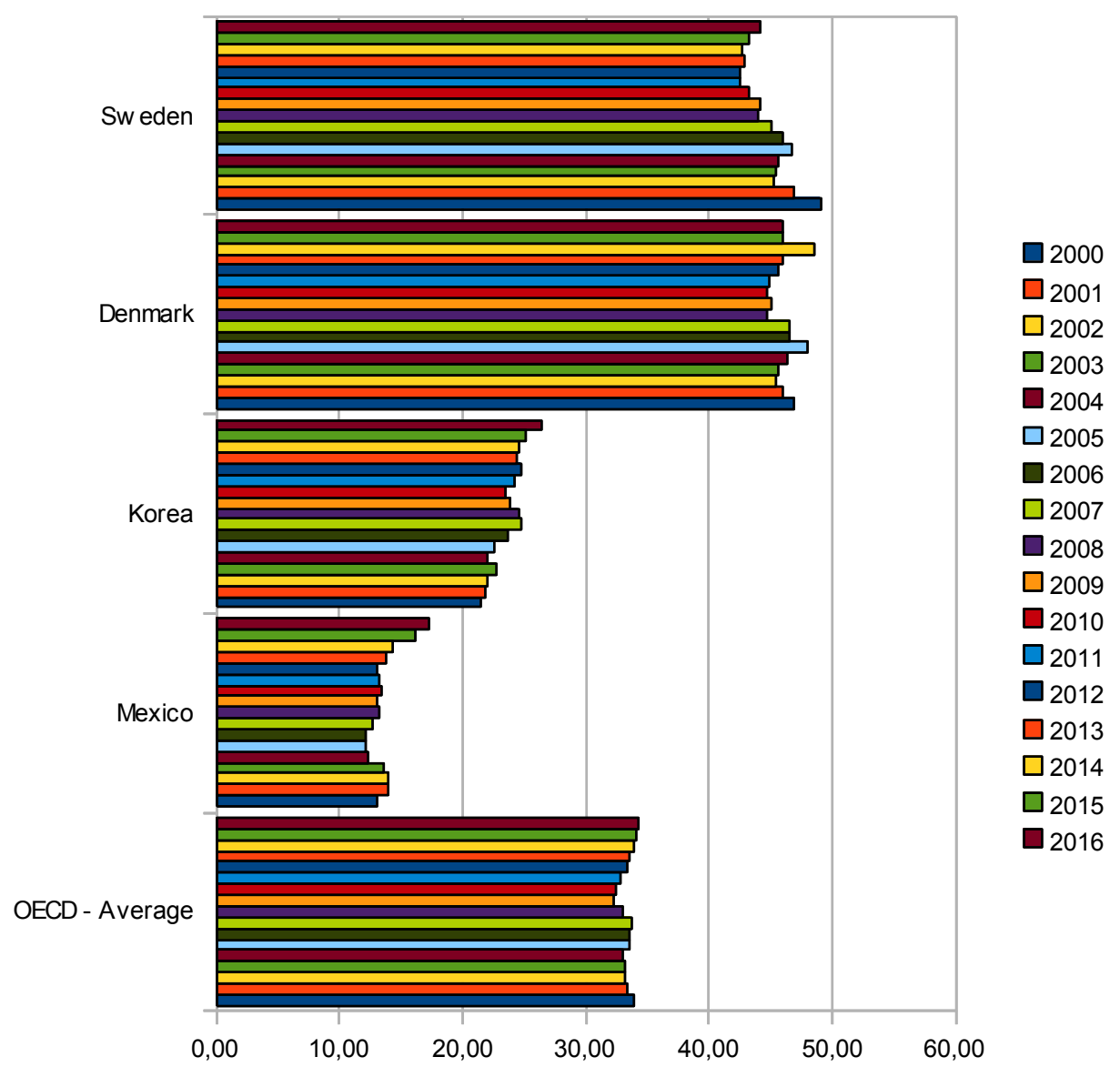

Fig. 2 below shows the tax to GDP ratio in OECD countries over the period 2000-2016. This indicator is known as fiscal pressure (or tax burden) and shows how heavy taxes are for taxpayers in each state.

Fig. 2. Tax to GDP ratio (\%), OECD countries, 2000-2016. Source: authors' construction

As expected, the level of the tax burden in OECD countries is slightly lower than the share of total budget revenue in GDP, because here we only consider the tax revenues. The lowest tax burden is recorded in Mexico (between 10-20\%), and Korea (between 20-30\%), and the highest level appears in Denmark and Sweden (40-50\%). The OECD average oscillated between 32-34\%. The average range of tax burden (between 30-40\%) contains 17 countries, while 10 countries were in the minimum range (10-30\%) and 8 countries in the maximum one (40-50\%) - especially among the Northern ones. In the minimum range, we find, as in Fig. 1, especially in non-EU countries. Then, in the middle one, we mainly find EU countries, with only three countries outside the EU (Israel, Canada, and New Zealand).

As we mentioned earlier, state interventionism can also be analyzed in terms of the share of public expenditure in GDP. The level of interventionism given by total public expenditure in OECD countries is shown in Fig. 3.

Thus, the interventionism level given by total expenditure is between $20-60 \%$. As in the case of revenues, we can delimit three intervals. The minimum range (20-40\%) includes 8 countries such as Australia, Estonia, Ireland, Japan, Korea, Latvia, Switzerland, and USA. In the middle range (40-50\%) we have 16 countries: Czech Republic, Germany, Greece, 
Hungary, Iceland, Israel, Italy, Luxembourg, the Netherlands, Norway, Poland, Portugal, Slovakia, Slovenia, Spain and UK. Then we have the countries: Austria, Belgium, Denmark, Finland, France, Ireland (2010) and Sweden in the maximum range (over 50\%). We mention that Ireland (2010) has the largest share of total expenditure in GDP, of $65 \%$. As before, we find in the minimum range mostly the non-EU countries, in the middle range are predominant the EU countries, and in the maximum one we have the Nordic countries and other developed EU countries. A high level of total public expenditure is justified as they have to support total revenues. Generally, states with a high level of interventionism in terms of tax revenues also have high interventionism through public expenditure and vice versa.

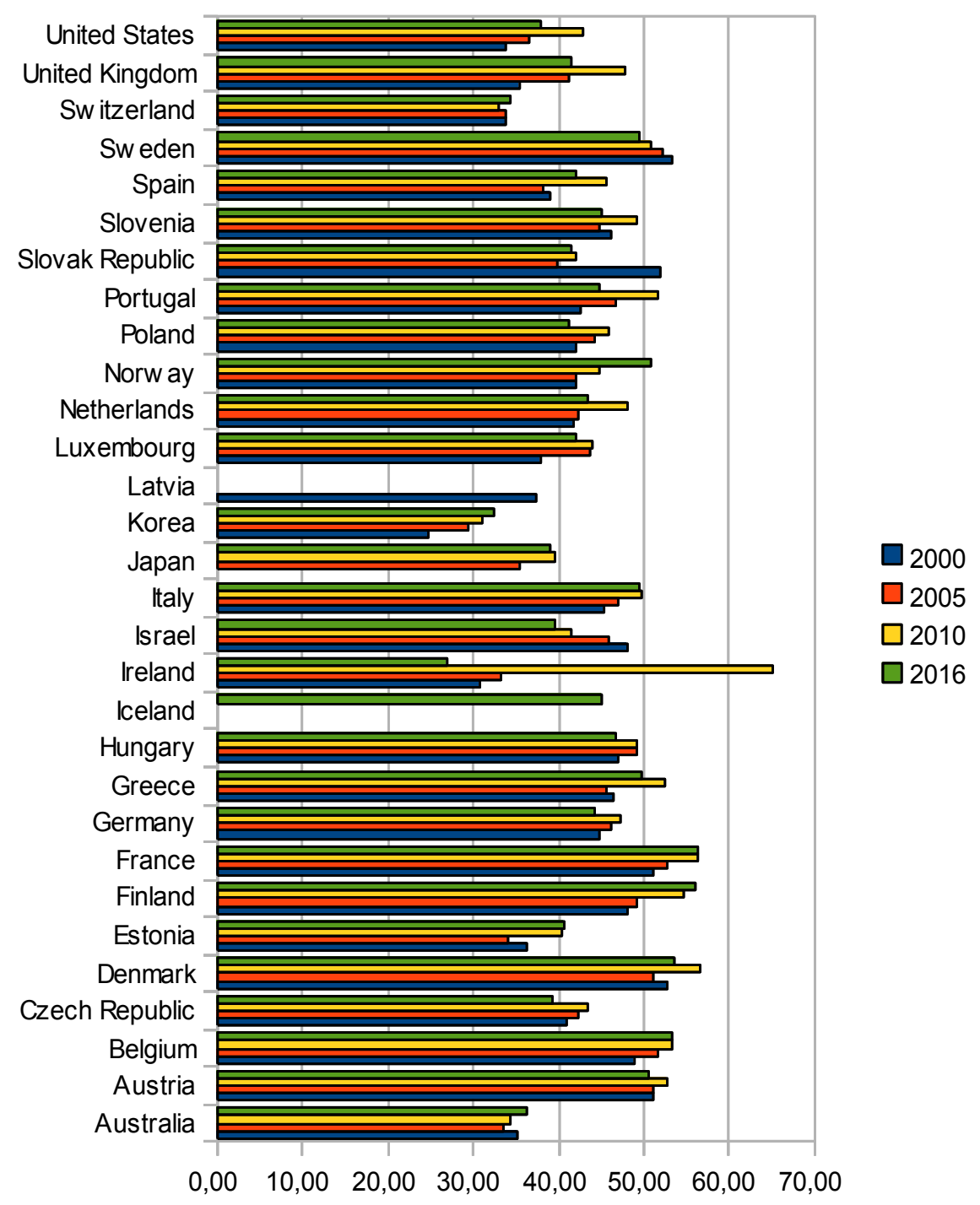

Fig. 3. Total general government expenditure (\%GDP) - OECD countries. Source: authors' construction 


\subsection{The Suggested model}

We used the panel econometrics, and the model takes the following form: (the form of the model and description of variables are according to Maşca et al. [8].

$$
\begin{aligned}
\text { IDit } & =c 0+c 1 \times \text { GDPit }+c 2 \times \text { FPit }+c 5 \times \text { EAit }+c 6 \times \text { SPit }+c 7 \times \text { EDit }+c 8 \times \text { HEit }+c 9 \\
& \times \text { GPit }+ \text { eit }
\end{aligned}
$$

Where:

ID - interventionism degree, GDP - gross domestic product, FP - fiscal pressure, EA economic affairs, $\mathrm{SP}$ - social protection, ED - education, HE - health, GP - general public services

Description of variables:

- $I D$ is the degree of interventionism in the $\mathrm{i}$ country $(\mathrm{i}=1, \ldots, 25)$, at $t$ moment $(t=2000, \ldots, 2016)$, calculated as a percentage ratio between the total government revenue and GDP (budget revenues are those of the consolidated general budget).

- GDP is the gross domestic product in $\mathrm{i}$ country, at $\mathrm{t}$ moment, representing a percentage of the total GDP of OECD countries. We expressed the state intervention by a relative measure which uses GDP and this requires the expression of the exogenous variable associated to GDP also in a relative form. We introduced this determinant in order to surprise the effect of the level of country development (expressed in relative terms) upon the degree of state intervention.

The following variables represent a proxy for the structure of public spending: expenditure with economic affairs, social protection, education, health and general public services. These are the most important categories of spending in the OECD countries budgets.

- EA represents the share of public expenditure with economic affairs in GDP in country i at moment $\mathrm{t}$.

- SP represents the share of social protection expenditure in GDP in country $i$ at time t.

- $E D$ is the share of public expenditure with education in GDP in country $i$ at time $t$.

- $H E$ is the share of public health expenditure in GDP in country $i$ at time $t$.

- GP is the share of general public services expenditure in GDP in country $i$ at time $t$.

To these exogenous variables a set of dummy variables is added. The dummy variables capture the particular characteristics associated to each country in the sample that can influence the degree of state intervention (for example - public policy or liberal orientations of governance).

We split the data into two groups of time categories. The first group is from 2000 to 2008, and from 2009 to 2016 . It seems that the coefficient of the time split is significant. This implies that there are two major sub periods.

The goodness of fit is $\mathrm{R}^{2}=0.8$.

Table 1. Estimates of model's parameters and their corresponding significance levels

\begin{tabular}{|l|r|r|r|r|r|}
\hline & \multicolumn{1}{|c|}{$\mathrm{B}$} & \multicolumn{1}{c|}{ Std. Error } & \multicolumn{1}{c|}{ Beta } & \multicolumn{1}{c|}{$\mathrm{t}$} & \multicolumn{1}{c|}{ Sig. } \\
\hline (Constant) & 1.190 & 1.383 & & 0.861 & 0.390 \\
\hline Health & 1.495 & 0.130 & 0.322 & 11.527 & 0.000 \\
\hline Education & 1.311 & 0.160 & 0.183 & 8.205 & 0.000 \\
\hline GDP \% of OECD & -0.226 & 0.028 & -0.225 & -8.194 & 0.000 \\
\hline Public services & 0.228 & 0.086 & 0.066 & 2.656 & 0.008 \\
\hline Social Protection & 0.686 & 0.058 & 0.412 & 11.796 & 0.000 \\
\hline Fiscal Pressure & 0.394 & 0.032 & 0.329 & 12.331 & 0.000 \\
\hline
\end{tabular}




\begin{tabular}{|l|r|r|r|r|r|}
\hline Period & -1.846 & 0.317 & -0.136 & -5.826 & 0.000 \\
\hline
\end{tabular}

It seems that all estimated coefficients are significant, except of Economic Affairs which was excluded from the regression model. Its estimated value was small negative 0.118 with $\mathrm{p}=0.181$.

The impact of time on interventionism degree is crucial. It seems that after 2008, the interventionism degree is smaller. The impact of Health (1.495), Education (1.311) Social Protection (.686) and Public services (.228) are positive. This means that these are the leading factors in governments' policies. The impact of the proportional GDP on the interventionism degree is negative which implies that the greater (on the average) the GDP the lower the interventionism degree is.

\section{Discussion}

As a result of analyzing the degree of state intervention in terms of budget revenues we found that EU well developed countries have a preference for a rather high level of total budget revenues as a percentage of GDP, which is found in the medium range (40-50\%), but also in the upper $(50-60 \%)$ - where we mostly find the Northern countries, known for their high level of taxation and, implicitly, of high budget revenues. Among the newer EU countries, only Hungary and Slovenia are in the middle range, the others following the trend from the non-EU countries such as Korea, New Zealand, the USA, and Mexico. Here the level of budget revenues is the lowest (mostly between 30-40\%).

So, we can say that, generally, well developed countries are characterized by a high level of state interventionism, while less developed ones by a lower interventionism. We also have some exceptions. In countries such as Japan, UK, USA, Australia, the degree of state intervention is lower, although they are developed countries. We are talking about their preference for a more liberal doctrine, with a less involvement of the state in economy.

Then we found that the interventionism level given by budget expenditure in OECD countries is between $20-60 \%$. As in the case of revenues we can delimit three intervals. The minimum range (20-40\%) includes 8 countries, in the middle range (40-50\%) we have 16 countries and then another 6 countries in the maximum range (over $50 \%$ ). As before, we find in the minimum range mostly the non-EU countries, in the middle range predominate the EU countries, and in the maximum one are the Nordic countries and other developed EU countries. A high level of total public expenditure is justified as they have to support total revenues. Generally, countries with a high level of interventionism in terms of tax revenues also have a high interventionism through public expenditure and vice versa.

We can also say that on average, OECD countries allocate about four times more money to social protection than to economic affairs. However, in some OECD countries such as Denmark, Finland, France, Germany, Greece, Italy, Israel, Portugal, Sweden and the UK, this threshold is exceeded. Also high interventionist countries such as: Denmark, Finland, France, Norway and Sweden invest heavily in social protection, well above the OECD average. On the other hand, less interventionist countries, such as the Czech Republic, Korea, Estonia, Slovakia, Slovenia, Hungary, Iceland and Luxembourg, support economic affairs with public money to a greater extent than the average.

\section{Conclusions}

The role of state intervention is analyzed in OECD countries. By standardizing and scaling economic variables such as GDP we could show which are the factors that affect the role of state on its own economy. It is shown that OECD countries can be classified by the extent of their tax burden, the state intervention and public expenditures policies. 
The study puts the light on the allocation of governmental resources among their own citizens. Well developed countries are characterized by a high level of state interventionism while less developed ones by a lower interventionism. OECD countries allocate about four times more money to social protection than to economic affairs on the average. In general, the tax burden in OECD countries after 2008 is smaller than before 2008.

Further analyses are needed, among them analysis of the suggested model such as full panel data amylases with respect to time and country. There is a room for dealing with more exploratory variables.

\section{References}

1. V. Tanzi , http://www.imf.org/external/pubs/ft/wp/wp97114.pdf, (1997)

2. A. Inotai, Z. Z Bakala, http://ceedinstitute.org/upload/files/960fd53a30ea5907d765107ac3557853.pdf, (2015)

3. C. F. Radu, Sci. J. Humanist. Stud., 8(5), 223-227 (2013)

4. P. Collier, http://www.iig.ox.ac.uk/output/articles/OxREP/iiG-OxREP-Collier.pdf, (2009)

5. V. Tanzi, http://www.iipf.org/speeches/Tanzi_2009.pdf, (2009)

6. G. Tabellini, Kyklos, 58(2), 283-303 (2005)

7. OECD, National Accounts at a Glance https://stats.oecd.org

8. S. G. Maşca, V. L. Văidean, A. Golguţ, ECTAP, XVIII, 5(558), 15-41 (2011) 